\title{
Development and Validation of RP-HPLC Method for Simultaneous Estimation of Diethylcarbamazine Citrate and Chlorpheniramine Maleate in Pharmaceutical Preparations
}

\author{
A. R. MAGESH and M. D. DHANARAJU* \\ Research Lab, GIET School of Pharmacy, \\ NH-16 Chaitanya Knowledge City, Rajahmundry, Andhra Pradesh, India \\ mddhanaraju@yahoo.com
}

Received 7 December 2016 / Accepted 21 December 2016

\begin{abstract}
Simple, precise and accurate HPLC method for diethylcarbamazine citrate and chlorpheniramine maleate was developed. The combination of DEC and CPM used effectively used to treat filariasis, tropical eosinophilia without causing allergic manifestations and is existing in tablet dosage form. HPLC separation was performed with a hypersil ODS-C18 $(5 \mu$, $250 \mathrm{~mm} \times 4.6 \mathrm{~mm}$, i.d) as a stationary phase and methanol: buffer $(55: 45 \mathrm{v} / \mathrm{v})$ as mobile phase, at a flow rate of $1.0 \mathrm{~mL} / \mathrm{min}$, UV detection was performed at $254 \mathrm{~nm}$. The retention time of chlorpheniramine maleate and diethylcarbamazine citrate were found to be 2.091 and $4.74 \mathrm{~min}$ respectively. Results of analysis were validated by recovery studies. Outcome of studies showed that the projected RP-HPLC method is simple, rapid, accurate and precise which can be used for regular determination of diethylcarbamazine citrate and chlorpheniramine maleate in bulk and its pharmaceutical dosage form.
\end{abstract}

Keywords: Diethylcarbamazine citrate, Chlorpheniramine maleate, HPLC

\section{Introduction}

Diethylcarbamazine citrate (DEC) chemically, N,N-dimethyl-4-methylpiperazine-1carboxamide dihyhydrogen citrate (Figure 1). It is a piperazine anthelmintic agent indicated for the management of individual patients with lymphatic filariasis, tropical pulmonary eosinophilia and loiasis. It exerts the mechanism by inhibiting arachidonic acid metabolism.<smiles>CCN(CC)C(=O)N1CCN(C)CC1</smiles>

Figure 1. Chemical structure of diethylcarbamazine citrate (DEC) 
Chlorpheniramine maleate (CPM) chemically known as (RS)-3-(4-chlorophenyl)-3(pyrid-2-yl) propyldimethylamine hydrogen maleate (Figure 2). It is an antihistamine drug that is commonly used in pharmaceutical preparations for symptomatic relief of common cold and allergic diseases. It inhibits the effects of histamine on capillary permeability and bronchial smooth muscle. It is a first generation alkylamine antihistamine used in the prevention of the symptoms of allergic conditions such as rhinitis and urticaria.<smiles>CN(C)CCC(c1ccc(Cl)cc1)c1ccccn1</smiles>

Figure 2. Chemical structure of chlorpheniramine maleate (CPM)

Literature survey reveals that chlorpheniramine maleate was determined by ultraviolet spectrophotometry $^{1-5}$, NMR spectroscopy ${ }^{6}$, polarographic ${ }^{7}$ and $\mathrm{HPLC}^{8-15}$ in pharmaceutical preparations.

Several analytical methods have been published for the determination of diethylcarbamazine citrate in tablets using HPLC $\mathrm{C}^{16-20}$ and gas chromatographic ${ }^{21}$ methods. The simultaneous determination of DEC and CPM was studied by Spectrophotometric ${ }^{22}$ and HPLC $^{23,24}$ methods.

In the present study the we have developed a simple, robust, precise and accurate RPHPLC method for the simultaneous determination of diethylcarbamazine citrate and chlorpheniramine maleate and validated as per $\mathrm{ICH}$ guidelines ${ }^{25}$.

The reported RP-HPLC method used Methanol: Buffer (55:45v/v) pH adjusted to 6.5 using sodium hydroxide as a mobile phase. The main aim of the work is to develop a method having less run time and shorter retention time than the reported methods and more sensitive compared to the developed method for analysis of diethylcarbamazine citrate and chlorpheniramine maleate formulation with low LOD and LOQ values.

\section{Experimental}

A HPLC (Schimadzu) method was developed using a Hypersil ODS-C18 (5 $\mu, 250 \mathrm{~mm} x$ $4.6 \mathrm{~mm}$, i.d) by means of a UV detector. The injection capacity of $20 \mu \mathrm{L}$ was used all through the analysis. The tablet Eofil Forte with $250 \mathrm{mg}$ of diethylcarbamazine citrate and $4 \mathrm{mg}$ of chlorpheniramine maleate was manufactured by Fourrts Laboratories Chennai. India. All other reagents used were of HPLC grade.

\section{Method development and optimisation}

The standard solutions containing diethylcarbamazine citrate and chlorpheniramine maleate were run and combinations of solvents were tried to get a good separation and stable peaks. From various mobile phases tried it was found that mobile phase containing methanol: buffer in the ratio $(55: 45)$ gave satisfactory result with sharp, well defined and resolved peaks with minimum tailing as compared to other mobile phases.

\section{Chromatographic conditions}

The optimised composition of the mobile phase was found to be methanol:buffer $(55: 45 \mathrm{v} / \mathrm{v})$ $\mathrm{pH}$ adjusted to 6.5 using sodium hydroxide. The flow rate was set to $1.0 \mathrm{~mL} / \mathrm{min}$ and UV detection was carried out at $254 \mathrm{~nm}$. The mobile phase was filtered through $0.45 \mu \mathrm{m}$ membrane filter and was sonicated before use. 
Preparation of phosphate buffer (6.5)

$13.80 \mathrm{~g}$ of Sodium dihydrogen phosphate monohydrate was dissolved in $900 \mathrm{~mL}$ of water. The $\mathrm{pH} 6.5$ was adjusted with sodium hydroxide and diluted with water to $1000 \mathrm{~mL}$. Sonicated it for 15 minutes to remove air bubbles.

\section{Preparation of stock solutions}

Diethylcarbamazine citrate standard stock solution $(250 \mu \mathrm{g} / \mathrm{mL})$

Stock solution was prepared by dissolving $250 \mathrm{mg}$ of accurately weighed quantity into $100 \mathrm{~mL}$ volumetric flask containing $50 \mathrm{~mL}$ of methanol. After complete solubilisation, the volume was made up to the mark with methanol. Now the concentration of this solution was $2500 \mu \mathrm{g} / \mathrm{mL}$. Suitable aliquot from this solution was further diluted to get a concentration of $250 \mu \mathrm{g} / \mathrm{mL}$.

\section{Chlorpheniramine maleate standard stock solution $(4 \mu \mathrm{g} / \mathrm{mL})$}

Drug stock solution was prepared by dissolving $4 \mathrm{mg}$ of accurately weighed quantity into 100 $\mathrm{mL}$ volumetric flask containing $50 \mathrm{~mL}$ of methanol. After complete solubilisation, the volume was made up to the mark with methanol. The standard stock solution was observed to contain 40 $\mu \mathrm{g} / \mathrm{mL}$. Suitable aliquot from this solution was further diluted to get a concentration of $4 \mu \mathrm{g} / \mathrm{mL}$.

Preparation of calibration curve of diethylcarbamazine citrate and chlorpheniramine maleate by appropriate dilution of the standard stock solution ,different dilution were prepared to obtain concentration ranging from $125-625 \mu \mathrm{g} / \mathrm{mL}$ for diethylcarbamazine citrate and $2-10 \mu \mathrm{g} / \mathrm{mL}$ for chlorpheniramine maleate. From these solution $20 \mu \mathrm{L}$ of each concentration was injected separately and the chromatograms were plotted. The detector was set at $254 \mathrm{~nm}$ and peak areas were recorded. The chromatograms of standard DEC and CPM are shown in Figure 3. The standard calibration curve was plotted separately as peak area versus respective concentrations of DEC and CPM. The linearity of both drugs was found to be in the acceptable range.

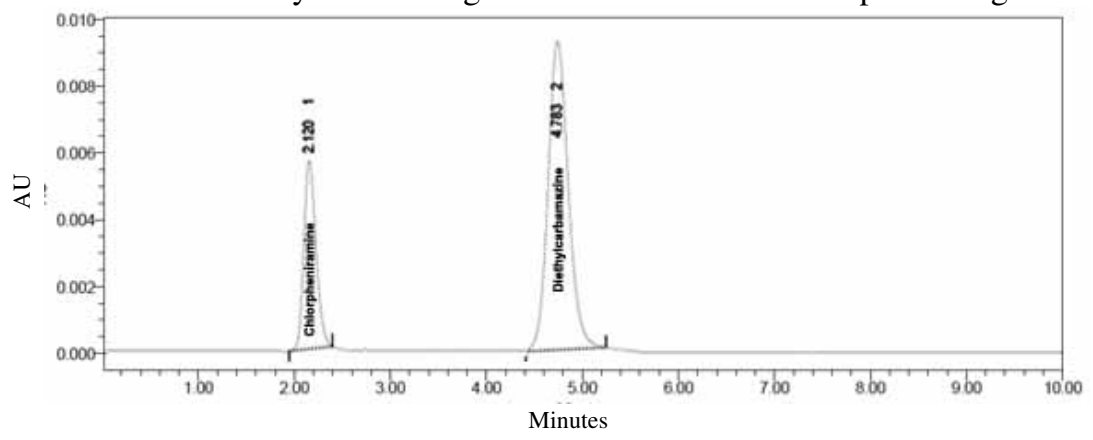

Figure 3. HPLC chromatogram of CPM and DEC

Standard calibration data for DEC and CPM are shown in Tables $1 \& 2$ and Figures 4 \& 5 respectively. Standard equation for DEC was found to be $\mathrm{y}=10.65 \mathrm{x}+34.23$, with correlation coefficient value of $\mathrm{R}^{2}=0.999$ and the standard equation for CPM was found to be $y=311.7 x+31.38$ with correlation coefficient value of $R^{2}=0.999$.

Table 1. Calibration table for DEC

\begin{tabular}{ccc}
\hline S.No & Concentration, $\mu \mathrm{g} / \mathrm{mL}$ & Peak area \\
\hline 1 & 125 & 1399 \\
2 & 250 & 2732 \\
3 & 375 & 4026 \\
4 & 500 & 5301 \\
5 & 625 & 6721 \\
\hline
\end{tabular}


Table 2. Calibration table for CPM

\begin{tabular}{ccc}
\hline S.No & Concentration, $\mu \mathrm{g} / \mathrm{mL}$ & Peak area \\
\hline 1 & 2 & 702 \\
2 & 4 & 1286 \\
3 & 6 & 1880 \\
4 & 8 & 2515 \\
5 & 10 & 3158 \\
\hline
\end{tabular}

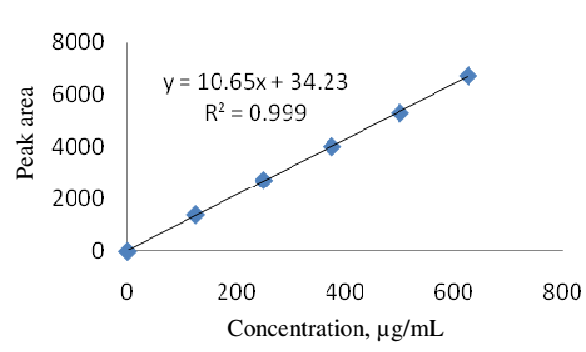

Figure 4. Calibration curve of DEC

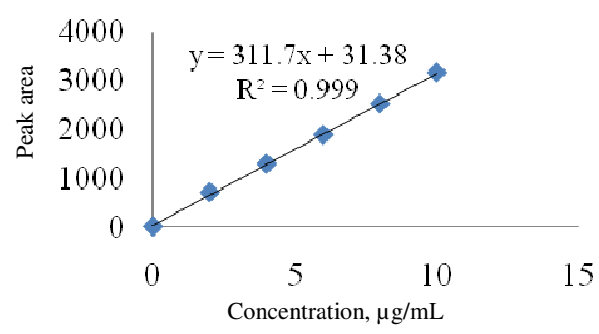

Figure 5. Calibration curve of CPM

\section{Preparation of sample solution from pharmaceutical dosage form}

Twenty tablets of DEC and CPM were exactly weighed, averaged and ultimately powdered. A quantity of powder equivalent to $250 \mathrm{mg}$ was weighed and transferred to a $100 \mathrm{~mL}$ volumetric flask containing $70 \mathrm{~mL}$ of methanol. The mixture was sonicated for 30 min to make sure absolute solubility of the drug and filtered through $0.45 \mu \mathrm{m}$ membrane filter and made up to the level with methanol. From the consequential solution appropriate aliquot was taken in a $10 \mathrm{~mL}$ volumetric flask and made up to the volume with methanol to get a final concentration of $4 \mu \mathrm{g} / \mathrm{mL}$ of CPM and $250 \mu \mathrm{g} / \mathrm{mLof}$ DEC.

\section{Results and Discussion}

Goal of this study was to develop a rapid, easy accurate, precise, reliable and least time consuming HPLC method for the analysis of diethylcarbamazine citrate and chlorpheniramine maleate in combined pharmaceutical formulation. The developed method has been validated as per ICH guidelines and has recommended the accomplishment of specificity, linearity, precision, accuracy and ruggedness of the method.

\section{Specificity}

It is the ability of an analytical method to assess unequivocally the analyte of interest in the presence of components that may be expected to be present, such as impurities, degradation products and matrix components. The proposed method is quite selective. There was no other interfering peak around the retention time of diethylcarbamazine citrate and chlorpheniramine maleate with no significant noise in the base line.

\section{Linearity}

A series of solutions were prepared from the stock solutions of DEC $(125-625 \mu \mathrm{g} / \mathrm{mL})$ and CPM $(2-10 \mu \mathrm{g} / \mathrm{mL})$ using the diluent and $20 \mu \mathrm{L}$ of each solution was injected in to the HPLC system and the peak area of the chromatogram was noted. A graph was drawn by taking the concentration of the drug on the $\mathrm{x}$-axis and the corresponding peak area on the y-axis. 
The linearity of an analytical method is its ability to obtain test results in direct or well defined athematical transformation proportional to the concentration of analyte in samples within a given range. It should be established across the range of analytical procedure. Linearity is generally represented as the correlation coefficient, the slope of regression line, etc. The results of linearity are given in Table 3.

Table 3. Linear regression data for calibration curve of DEC and CPM

\begin{tabular}{ccccc}
\hline Drug & $\begin{array}{c}\text { Linearity range, } \\
\mu \mathrm{g} / \mathrm{mL}\end{array}$ & Slope & Intercept & $\begin{array}{c}\text { Correlation } \\
\text { coefficient }\end{array}$ \\
\hline DEC & $125-625$ & 10.65 & 34.23 & 0.999 \\
CPM & $2-10$ & 311.7 & 31.38 & 0.999 \\
\hline
\end{tabular}

\section{Precision}

Intraday and Interday precision study of DEC and CPM was conceded out by estimating the resultant response 5 times on the same day and on 5 different days for the concentration of $250 \mu \mathrm{g} / \mathrm{mL}$ for DEC and $4 \mu \mathrm{g} / \mathrm{mL}$ for CPM. The $\%$ RSD obtained under different conditions were found to be less than $2 \%$. The result of precision study is shown in Table 4 and Table 5 respectively.

Table 4. Precision study of diethylcarbamazine citrate

\begin{tabular}{cccc}
\hline S.No & Concentration & $\begin{array}{c}\text { Intraday precision } \\
\text { (Peak area) }\end{array}$ & $\begin{array}{c}\text { Interday precision } \\
\text { (Peak area) }\end{array}$ \\
\hline 1 & 250 & 2721 & 2743 \\
2 & 250 & 2735 & 2758 \\
3 & 250 & 2691 & 2731 \\
4 & 250 & 2746 & 2754 \\
5 & 250 & 2751 & 2763 \\
6 & 250 & 2743 & 2765 \\
Mean & & 2731.16 & 2752.30 \\
Standard & & 22.35 & 13.04 \\
Deviation & & 0.81 & 0.47 \\
\% RSD & & &
\end{tabular}

Table 5. Precision study of chlorpheniramine maleate

\begin{tabular}{cccc}
\hline S.No & Concentration & $\begin{array}{c}\text { Intraday precision } \\
\text { (Peak area) }\end{array}$ & $\begin{array}{c}\text { Interday precision } \\
\text { (Peak area) }\end{array}$ \\
\hline 1 & 4 & 1347 & 1387 \\
2 & 4 & 1325 & 1378 \\
3 & 4 & 1337 & 1375 \\
4 & 4 & 1341 & 1365 \\
5 & 4 & 1361 & 1369 \\
6 & 4 & 1329 & 1357 \\
Mean & & 1340 & 1371.8 \\
Standard & & 13.01 & 10.51 \\
Deviation & & 0.97 & 0.76 \\
\% RSD & & &
\end{tabular}




\section{Accuracy}

To establish the accuracy of the projected method, recovery studies were performed out in triplicate by spiking different concentrations of bulk drug with pre-analysed formulation with three different concentrations of standard containing $80 \%, 100 \%$ and $120 \%$ of the pure drug. The percentage recovery obtained was found to be in the acceptable range as shown in Table 6.

Table 6. Accuracy study of diethylcarbamazine citrate and chlorpheniramine maleate

\begin{tabular}{cccc}
\hline Drug & Level\% & \% Recovery & \% R.S.D \\
\hline \multirow{3}{*}{ DEC } & 80 & 99.79 & 0.032 \\
& 100 & 99.55 & 0.056 \\
& 120 & 100.22 & 0.025 \\
\hline \multirow{2}{*}{ CPM } & 80 & 99.89 & 0.087 \\
& 100 & 100.32 & 0.029 \\
& 120 & 99.64 & 0.045 \\
\hline
\end{tabular}

\section{Sensitivity}

The sensitivity of measurement of CPM and DEC for the proposed method was evaluated in terms of limit of detection and limit of quantification. The LOD and LOQ were determined as per ICH guidelines.

\section{Conclusion}

The proposed method was found to be simple, precise, accurate and robust for the estimation of DEC and CPM in pure and its pharmaceutical dosage form was developed and validated. The method has been found best than from few methods reported. Based on the results, it can be concluded that above developed RP-HPLC method is appropriate for the determination of diethylcarbamazine citrate and chlorpheniramine maleate in tablet formulation. Hence, this method can be used in routine quality control for analysis of DEC and CPM in bulk and its dosage forms.

\section{Acknowledgement}

We are grateful to the Management and Principal, GIET School of Pharmacy, India for providing the necessary facilities to perform the work.

\section{References}

1. Wadher S J, Kalyankar T M and Panchal P P, Int J Chem Tech Res., 2013, 5(5), 2410-2419.

2. Khalode K D, Waikar S B and Padmane S P, Int J Pharm Technol., 2012, 4(3), 4690- 4699.

3. Ekram M H, Mohamed S M and Ruba N S, J Pharm Biomed Sci., 2011, 7(7), 1-9.

4. Arun K, Vikas G, Roy G S and Monika K, Int Curr Pharm J., 2013, 2(5), 97-100.

5. Joshi R S, Pawar N S and Sawant R L, Lat Am J Pharm., 2010, 29(7), 1226-1230.

6. Hanna G M and Lau-Cam C A, J Pharm Biomed Anal., 1993, 11(9), 855-859; DOI:10.1016/0731-7085(93)80080-K

7. Teraboon P, Saisunee L and Boonsom L, Chiang Mai J Sci., 2007, 34(1), 135-142.

8. $\quad$ Sandeep R, Int J Life Sci Pharm Res., 2011, 1(1), 94-100. 
9. Hamide C and Tuncel O, J Chrom Sci., 2002, 40(2), 97-100; DOI:10.1093/chromsci/40.2.97

10. Redasani V K, Gorle A P, Badhan R A, Jain P S and Suranav S J, Chem Ind Chem Eng Quart., 2013, 19(1), 57-65.

11. Abdulbari M M and Ihsan M S H, Int J Pharm Pharm Sci., 2013, 5(3), 666-670.

12. Marin A, Garcia E, Garcia A and Barbas C, J Pharm Biomed Anal., 2002, 29(4), 701714; DOI:10.1016/S0731-7085(02)00124-3

13. Maithani M, Richa R, Vertika G, Dharmendra K and Amrendra K C, Pharmacie Globale (IJCP)., 2010, 5(5), 1-4.

14. Geetha laxmi E and Ramasamy R, Int J Pharm Pharm Sci., 2012, 4(3), 588-591.

15. Qi P M L, Wang X, Leng J L and Gu R N, Chromatographia., 2002, 56(5), 295-301; DOI:10.1007/BF02491935

16. Boopathy D, Devaki M, Arun K B, Sekar V and Perumal P, Asian J Res Chem., 2011, 4(7), 1064-1067.

17. Mahesh R J , Jeyaprakash M R, Madhuri K, Meyyanathan S N and Elango K, Indian J Pharm Sci., 2011, 73(3), 320-323.

18. Krishna V M, Jayalakshmi B, Vijay A R and Sandeep C, Int J Pharm Sci Res., 2012, 3(9), 3347-3353; DOI:10.13040/IJPSR.0975-8232.3(9).3347-53

19. Nisha $\mathrm{M}$ and Kalyanasundaram M, Acta Trop., 2001, 80(2), 97-102; DOI:10.1016/S0001-706X(01)00163-2

20. Chandrasekaran B, Patil S K and Harinath B C, Indian J Med Res., 1978, 67, 106-109.

21. Miller J R and Fleckenstein J L, J Pharm Bio Anal., 2011, 26(4), 665-674; DOI:10.1016/S0731-7085(01)00435-6

22. Gouru S R, Bhaskar D and Kamarapu S K, Int J Pharm Biol Sci., 2013, 3(4), 216-223.

23. Bhaskar D, Santosh Reddy G and Kamarapu S K, Asian J Pharm Clin Res., 2014, 7(4), 98-102.

24. Shah D A, Doshi S S, Baldania S L, Chhalaotiya and Bhatt K K, Turk J Pharm Sci., 2014, 11(1), 79-86.

25. ICH Validation of Analytical Procedures: Text and Methodology, Q2 (R1), International Conference on Harmonisation, 2005. 